\title{
Wasiat Pendidikan Sufistik Dalam Naskah Tanbih Mursyid Tarekat Qodiriyyah Naqsyabandiyah Suryalaya (Telaah Pemikiran Guru Mursyid Tqn Suryalay)
}

\author{
Ach. Sayyi \\ (Dosen STAI Al-Khairat Pamekasan, \\ e-mail:sayyid.achmad17@gmail.com)
}

\begin{abstract}
Abstrak
Pendidikan sufi ini menjadi sangat penting dan sangat dibutuhkan oleh individu dan masyarakat. Karakter moral masyarakat yang lemah perlu dikembangkan lebih jauh melalui berbagai cara yaitu pendidikan sufi secara vertikal adalah moral dan penyembahan kepada Allah, dan secara horizontal merupakan moral yang baik bagi sesama makhluk. Beberapa contoh hal yang dapat meningkatkan tingkat moral dan karakter adalah; Pertama, pendidikan awal dalam keluarga menanamkan karakter sejak dini oleh orang tua dan lingkungan sekitar seperti kejujuran, tanggung jawab, keberanian, sopan santun, rendah hati, murah hati dan sebagainya. Kedua, mengadakan kegiatan spiritual seperti pembacaan rutin, Kelahiran Nabi, habituasi zikir / wird setelah sholat. Ketiga, mengadakan pelatihan (Riyadlah) dalam bentuk munajat kepada Allah SWT. Murshid Tanbih TQN Suryalaya pada dasarnya menawarkan rangkaian solusi untuk mewujudkan pendidikan yang menekankan nilai-nilai penciptaan manusia yang sempurna.
\end{abstract}

\begin{abstract}
Abstrak
This Sufi education becomes very important and much needed by individuals and society. The weak moral character of society is needs to be developed further through many ways which is Sufi education vertically is morals and worship Allah properly, and horizontally is a good moral to fellow beings. Some examples of things that can increase the level of moral and character is; First, the early education in families instill character early on by parents and the surrounding environment such as honesty, responsibility, courage, courtesy, humble, generous and so forth. Second, hold spiritual activities such as regular recitation, Birth of the Prophet, habituation zikir / wird after prayer. Third, hold trainings (Riyadlah) in the form of munajat to Allah SWT. Murshid Tanbih script TQN Suryalaya essentially offers a suite of solutions to realize education that emphasizes the values of the creation of perfect man.
\end{abstract}

Keywords : Education Sufic, Tanbih, Murshid TQN. 


\section{Pendahuluan}

Saat ini pandangan manusia tentang nilai-nilai kemanusiaan telah bergeser menuju suatu yang bersifat materialistik sehingga sangat wajar apabila nilai-nilai tersebut hampir punah. Berbagai macam persoalan yang terjadi di masyrakat, seperti pemiskinan, korupsi, aksi terorisme, merupakan akibat secara tidak langsung bahwa nilai-nilai kemanusiaan dalam kehidupan manusia sendiri semakin menipis.

Salah satu upaya untuk meredam fenomina tersebut, maka banyak bermunculan para peneliti yang menawarkan solusi, hal ini sebagaimana yang ditawarkan oleh Muhaimin ${ }^{1}$ dengan kesimpulan bahwa prestasi belajar pada orang dewasa naik lebih cepat untuk hal-hal yang lebih abstrak, dan naik lambat untuk hal-hal yang bersifat konkrit. Ia juga menyimpulkan bahwa semakin bertambah usia orang dewasa semakin luas, beragam, dan tinggi kualitas prestasinya. Miles menyimpulkan dari hasil penelitiannya bahwa latihan dan praktek dapat mempertahankan status mental seseorang.

Berdasarkan hasil penelitian Muhaimin tersebut dapat dipahami bahwa kualitas prestasi iman seseorang yang merupakan hal yanga lebih bersifat abstrak, akan dapat semakin meningkatkan lebih cepat dan bahkan memiliki wawasan iman dan taqwa yang lebih luas dan mendalam kalau ia telah dewasa, atau setidak-tidaknya tetap bertahan dalam menghadapi berbagai cobaan hidup, bila mana ia selalu meningkatkannya dalam bentuk praktek (amal saleh) dan latihan-latihan yang bersifatruhaniyah (riyadlah) sepertihalnyapuasa, sodaqohdan lain sebagainya.

Masih dari hasil temuan Muhaimin mengemukakan bahwa manusia itu terdiri atas tiga aspek utama; Pertama, Aspek Jasmiyah, yaitu keseluruhan organ fisikbiologis, sistem kalenjar, dan sistem syaraf;Kedua, Aspek Nafsiyah, yaitu keseluruhan kualitas insani yang khas dimilik manusia, yang mengandung dimensi al-nafs, alaql, dan al-qalb:danKetiga, Aspek Ruhaniyah yaitu keseluruhan potesi luhur psikis manusia yang memancarkan dari dimensi al-ruh, dan al-fitrah. ${ }^{2}$

Dalam undang-undang no. 20 Tahun 2003 dijelaskan bahwa Sistem Pendidikan Nasional adalah mencerdaskan kehidupan bangsa dan mengembangkan manusia seutuhnya, yaitu manusia yang beriman dan bertaqwa kepada Tuhan yang Maha Esa...

\footnotetext{
${ }^{1}$ Muhaimin, Wacana Pengembangan Pendidikan Islam, (Yogyakarta: Pustaka Pelajar, 2003), 148

${ }^{2}$ Muhaimin, Wacana Pengembangan.., 149
} 
kehidupan manusia di dunia adlah sebagai wakil Allah SWT. Seperti yang telah Allah firmankan dalam Al-Qur'an Surat Al-Baqarah ayat 30 yang artinya:

"Ingatlah ketika Tuhanmu berfirman kepada para malaikat: Sesungguhnya Aku hendak menadikan seorang khalifah di muka bumi, mereka berkata; Kenapa Engkau hendak menadikan (khalifah) di bumi orang itu yang akan membuat kerusakan padanya dan menumpahkan darah, padahal kami senantiasa bertasbih dengan memui Engkau dan mensucikan Engkau? Tuhan berfirman: "Sesungguhnya Aku mengetahui apa yang tidak kamu ketahui"."

Ayat di atas menerangkan bahwa manusia sebagai pengganti dan penerus (species) yang mendahuluinya, pewaris-pewaris di muka bumi. Di samping itu manusia adalah pemikul amanah yang semula ditawarkan pada langit, bumi, dan gunung yang semua enggan menerimanya, namun dengan ketololannya manusia mau menerima amanah it, serta menjadi pemimpin atas diri sendiri, keluarga dan msyrakat. Semuanya itu merupakan atribut dari fungsi manusia sebagai "khalifah Allah" dimuka bumi ${ }^{4}$.

Dalam dunia pendidikan khususnya di Indonesia saat ini kian marak institusi yang lebih mengedepankan rasionalitas dari pada religiutas. Disinlah peran Agama, Norma Masyrakat, budaya dan adat istiadat yang selaras dengan nilai-nilai jati diri bangsa yang msemestinya dikedepankan. Sebagaiman diketahuai, pendidikan agama (Islam) adalah pendidikan yang memberikan pengetahuan dan membentuk sikap, kepribadian, dan keterampilansiswa dalam mengamalkan ajaran agamanya, yang dilaksanakan sekurang-kurangnya melalui mata pelajaran/kuliah pada semua jalur jenjang dan jenis pendidikan. Maka dari itu, keseluruhan ajaran dari agama, moral dan norma yang berdimensi positif dapat digunakan sebaga akar dari pendidikan karakter. ${ }^{5}$

Pendidikan Sufistik ini menjadi hal yang sangat penting dan sangat dibutuhkan oleh individu maupun masyrakat. Moral dan karakter masyrakat yang lemah perlu dikembangkan lagi melalui banyak cara karena bentuk pendidikan Sufistik secara vertikal adalah berakhlak dan beribadah kepada Allah SWT dengan baik, dan secara horizontal adalah berakhlak baik kepada sesama makhluk. Beberapa contoh hal yang

\footnotetext{
${ }^{3}$ Depertemen Agama RI, Al-Quran dan terjamahannya, yayasan penyelenggaraan penafsir/penerjamah Al-Qur'an.6

${ }^{4}$ Muhaimin, Pemikiran Pendidikan Islam; Kajian Filosofis dan kerangka Dasar Operasionalisasinya. Bandung: PT Triganda Raya, 1993.,.61

${ }^{5}$ Aswan Sahlan, Desain Pembelajaran Berbasis Pendidikan Karakter, Yogyakarta: Ar-Ruzz Media, 2012.,. 16
} 
dapat meningkatkan tingkat moral dan akhlak adalah; Pertama, dengan pendidikan sejak dini dalam keluarga menanamkan karakter sejak dini oleh orang tua dan lingkungan sekitar seperti bersikap jujur, tanggung jawab, pemberani, sopan santun, rendah hati, dermawan dan lain sebagainya.Kedua, mengadakan kegiatan kerohanian seperti pengajian rutin, Maulid Nabi, pembiasaan zdikir/wirid setelah shalat.Ketiga, mengadakan pelatihan-pelatihan (Riyadlah) dalam bentuk munajat kepada Allah SWT.

Ahmadi $^{6}$ mengemukakan bahwa Pendidikan Islam harus memuat materi yang dapat mengantarkan subyek didik ke tujuan akhir yakni, ma'rifatullah dan ta'abdillah (menguatkan keimanan dan ibadah kepada Allah SWT), mampu berperan sebagai khalifatullah fi al-ard dan memperoleh kebahagiaan hidup di dunia dan akhirat. ${ }^{7}$

Untuk mewujudtkan tujuan akhir dari prndidikan Islam sebagaimana di atas, maka perlua adanya pencerahan hati bagi setiap indivdu dan masyrakat melalui ilmu tasawuf (pendidikan Sufistik) yang pada hakikatnya merupakan implementasi dari rukun Agama Islam yang ketiga, yakni Ihsan.Pendidikan Sufistiksangat dibutuhkan oleh setiap individu maupun masyarakat, karena pengaruh positifnya yang indah akan dirasakan oleh individu dan masyarakat dalam porsi yang sama, sebagaimana dampak negatifnya, ketika ia diremehkan, akan menyebar kepada individu dan masyarakat dan bentuk pendidkan sufistik secara vertikal adalah dapat berakhlak dan beribadah dengan baik kapada Allah SWT dan secara horizontal berakhlak baik kepada setiap mahluk. Seperti tawuran para pelajar yang terjadipadaakhir-akhirini, terjangkit obat-obatan terlarang, dan bergaya hidup bebas dan pergaulan bebas, hal ini yang sangat meresahkan kaum terdidik dan pendidik. Oleh karena itu pendidikan sufistik ini harus diperhatikan sejak awal marhalah(fase) umur manusia, yaitu dari sejak masa kanak-kanak. Ibnu Qoyyim berkata mengenai hal ini, “ yang sangat dibutuhkan oleh anak adalah perhatiannya kepada akhlak."8

Pendidikan Sufistik dalam naskah Tambih Mursyid Tarekat Qadiriyah Naqsyabandiyah (TQN) ini, tentunya juga dalam rangka ikut andil untuk meminimalisir

\footnotetext{
${ }^{6}$ Ahmadi, Ideologi Pendidikan Islam, Pradigma Humanisme Teosentris, Yogyakarta: Pustaka Pelajar, 2005.,.12

7. Sejak awal budaya, pendidikan pada hakikatnya merupakan proses sosialisasi dan inkulturasi yang menyebarkan nilai-nilai dan pengetahuan yang terakumulasi dalam masyrakat. Perkembangan msyrakat berjalan dengan pertumbuhan dan proses sosialisasi dan ingkulturasinya dalam bentuk yang bisa diserap secara optimal. Lihat: Said Aqil Syiraj, Tasawuf Sebagai Kritik Sosial, mengedepankan Islam sebagai infirai, bukan Asfirasi, Bandung, Mizan, 2006. ,. 25

${ }^{8}$ Hasan Bin Ali Al-Hijazi, Manhaj Tarbiyah Ibnu Qoyyim, (Jakarta: Pustaka Al-Kausar, 2001), ,. 207.
} 
atas segala fonomena tersebut di atas. Tanbih adalah nasihat agama yang diberikan oleh seorang Guru Mursyid dalam wujud perintah (wasiat) yang disebarkan untuk semua murid-muridnya ${ }^{9}$. Sedangkan Mursyid itu sendiri adalah pemimpin, pembimbing dan pembina murid-muridnya dalam kehidupan lahiriah dan pergaulan sehari-hari supaya tidak menyimpang dari ajaran-ajaran Islam dan terjerumus kedalam maksiat seperti berbuat dosa besar atau dosa kecil, selain itu juga tugas mursyid adalah memimpin, membimbing dan membina murid-muridnya melaksanakan kewajiban yang ditetapkan oleh syara' dan melaksanakan amal-amal sunnah untuk bertaqarrub mendekatkan dirikepada Allah SWT. Disamping memimpin yang bersifat lahiriah tersebut, seorang mursyid adalah juga pemimpin kerohanian bagi murid-muridnya, menuntun dan membawa murid-muridnya kepada tujuan tarikat guna mendapatkan ridla Allah $\mathrm{SWT}^{10}$.

Sementara Tarekat ialah suatu pembimbingan pribadi dan prilaku yang dilakukan seorang Mursyid kepada muridnya. Sedangkan Tarekat Qadiriyyah WaNaqsyabandiyyah (TQN) Suryalaya adalah dua tarekat yang berbeda, baik pendirinya maupun bentuk ajarannya. Tarekat Qadiriyyah berasal dari Syeikh Abd Qadir Jailani Sedangkan tarekat Naqsyabandiyyah berasal dari tarekat yang dinisbahkan kepada seorang sufi besar bernama Muhammad Ibn Muhammad Bahauddin al Uwaisi al-Bukhari al Naqsabandi. Perpaduan dua tarekat ini merupakan jasa dari seorang ulama Indonesia yang berasaldari Sambas Kalimantan Barat bernamaSyeikh Ahmad Khatib As Sambasi (lahirtahun $1802 \mathrm{M}$ ), yang bermukim dan meninggal di Mekkah pada tahun $1878 \mathrm{M}^{11}$

\section{Metode Penelitian}

Jenis penelitian ini termasuk penelitian pustaka (library research). Yang berusaha mengkaji berupa, kitab, buku, jurnal dan lain sebagainya yang bersifat tulisan yang berhubungan dengan topic penelitian terutama karya Mursyid TQN Suryalaya

\footnotetext{
${ }^{9}$ Sri Mulyati, Peran Edukasi Tarekat Qadiriyyah Naqsyabandiyah dengan Refrensi utama Suryalaya, (Kencana, Jakarta: 2010) ,. 217

${ }^{10}$ Mursyid pada hakikatnya adalah sahabat rohani yang sangat akrab sekali dengan rohani muridnya yang bersama-sama tak bercerai-cerai, beriring- iringan, berimam-imaman melaksanakan zikrullah dan ibadat lainnya menuju ke hadirat Allah SWT. Persahabatan itu tidak saja semasa hidup di dunia, tetapi persahabatan rohaniah ini tetap berlanjut sampai ke akhirat, walaupun salah seorang telah mendahului berpulang ke rahmatullah, dan telah sederetan duduknya dengan para wali Allah yang saleh. Kadirun Yahya, Penjelasan Tentang Wasilah dan Mursyid, Universitas Panca Budi Medan, 1982),15-16

${ }^{11}$. Hawas Abdullah, Perkembangan Ilmu Tasawuf dan Tokoh-tokohnya di Nusantara, Surabaya, al Ikhlas, 1980, hal 177.
} 
(KH. Abdullah Mubarok bin Nur Muhammad yang dikenal dengan sebutan "Abah Sepuh" dan KH. A. Shohibulwafa Tajul Arifin yang dikenal dengan sebutan "Abah Anum"). Dalam library research ini, penulis akan menggunakan penelitian deskriptif dengan lebih menekankan pada kekuatan analisis sumber dan data yang ada, dengan mengandalkan konsep yang ada untuk diinterpretasikan. ${ }^{12}$

Sumber data ada dua yaitu: Pertama, sumber primer adalah kitab karya Mursid TQN Suryalaya (Tanbih Mursyid TQN, Miftahu as-Shudur, Akhlaq al-Karimah fii Mudawami ad-dzikri,Risalah Tuntunan Tarekat Qadiriyyah wa Naqsyabandiyah, 'Uqudul al-Juman). Kedua, sumber sekunder adalah kitab Sabil alMuhtadin li Ma'rifat al-Thariqah wa Kaifiyyat Amaliha min al-Qadiriyyah wa alNaqsyabandiya;Al-Qunyah Li Talibi Thariqah fi al-Ahlaq wa al-Tashawwuf wa alAdaB AL-Islamiyah; Al-Fath al-Rabbani; Sirr al-Asrar fi Ma Yahtaj ilayhal-Abrar;AlFutuhat al-Rabbaniyyah fi al-Thariqath al-Qadiriyyah wa an-Naqsyabandiyah, dan “Thariqath Qadiriyyah Naqsyabandiyyah” Sejarah Asal Usul dan Perkembangannya, sertaberbagai leteratur diera kekinian baik buku maupun jurnal yang berkaitan dengan penelitian ini.

Analisis data yang akan digunakan di dalam penelitian ini adalah analisis isi (content analysis) yang bersumber dari hasil eksplorasi data kepustakaan. Dalam hal penelitian ini menggunakan 6 tahapan analisis isi, yaitu: unitizing, sampling, recording, reducing, abductively inferring, dan naratting. ${ }^{13}$

Penelitian ini akan menggunakan kredibilitas sebagai upaya pengecekan keabsahan data penelitian. Kredibilitas data adalah mengkonfirmasi serta memverifikasi data penelitian yang telah didapat kepada subyek penelitian sehingga keaslian dan keobjektifan data dapat terjamin tanpa ada rekayasa. ${ }^{14}$ Oleh karena itu, upaya yang akan dilakukan peneliti dalam mengecek kredebilitas data penelitian ini adalah dengan tehnik triangulasi data, meningkatkan ketekunan, diskusi teman sejawat, dan kecukupan bahan

\footnotetext{
12 Soejono dan Abdurrahman, Metode Penelitian suatu Pemikiran dan Penerapannya (Jakarta: Reneka Cipta, 1999), 25.

Penelitian Deskriptif secara khusus bertujuan untuk (1) Memecahkan masalah- masalah aktual yang dihadapi sekarang ini, dan (2) mengumpulkan data dan informasi unuk disusun, dijelaskan dan dianalisis. Lihat S. Margono, Metodologi Penelitian Pendidikan (Jakarta: PT Asdi Mahasatya, Cet, ke-2, 2000), 8

13 Klaus Krippendorff, Content Analysis: An Introductions to its Methodology (Second Edition) (California: Sage Publication, 2004), 27

14 Arief Furchan dan Agus Maimun, Studi Tokoh: Metode Penelitian Mengenai Tokoh (Yogyakarta: Pustaka Pelajar, 2005), 7.
} 
referensi. ${ }^{15}$ Peneliti akan membandingkan data-data dalam bentuk karya-karya yang ditulis oleh Mursyid TQN Suryalaya yang berkenaan dengan Urgensi Pendidikan Sufistik dengan beberapa tulisan orang lain mengenai pemikiran Mursyid TQN Suryalaya tentang paradigma tersebut.

\section{Biografi Mursyid TQN Suryalaya dari masa ke masa}

1. Biografi Abah Sepuh

Abah Sepuh bernama asli Abdullah Mubarok Bin Nur Muhammad, lahir pada tahun 1836 di Desa Cicalung Bojongbenteng Pagerageung Tasikmalaya. Ayahnya bernama Raden Nur Muhammad alias Nurpraja atau dikenal dengan Eyang Upas. Sedangkan ibunya bernama Emah. Keluarga ini mempunyai kedudukan terhormat di masyarakat saat itu. ${ }^{16} \mathrm{Abah}$ Sepuh semenjak kecil semangat mencari ilmu, dengan fokus mempelajari fiqih dan linguistik arab (nahwu-shorof) di Pondok Pesantren Sukamiskin Bandung. Beriringan dengan perkembangan kedewasaannya, Abah Sepuh belajar ilmu Tasawuf di Kalisapu Cirebon dengan berguru langsung kepada Syaikh Tolhah ${ }^{17}$ selama 23 tahun dan sekaligus pernah belajar ke Syaikh Cholil Bangkalan Madura. Waktu itu teman santri Abah Sepuhadalah tokoh-tokoh kyai besar masa depan, seperti Hasyim As'ari dari Tebu Ireng, Wahab Hasbullah dari Jombang, Manaf Abdul Karim dari Lirboyo, Muhammad Shidiq dari Jember, Munawir Krapyak dari Yogyakarta, dan Maksum dari Rembang. ${ }^{18}$

Abah Sepuh juga pernah mendapatkan bai'at Tarekat Qodiriyah Naqsyabandiyah dari Syekh Abdul Karim Banten ketika sedang belajar di Mekkah. Namun yang secara intens mengajarkan ilmu tasawufnya adalah Syaikh Tolhah. Pada tahun 1890, Abah Sepuh sudah kembali ke tanah kelahirannya, Tasikmalaya, dan membentuk kelompok pengajian pada usia 54 tahun. Kemudian pada tahun

\footnotetext{
${ }^{15}$ Nurul Ulfatin, Metode Penelitian Kualitatif Di Bidang Pendidikann: Teori Dan Aplikasi, 271-275.

${ }^{16}$ Unang Sunardjo, Menelusuri Perjalanan Sejarah Pondok Pesantren Suryalaya Pusat Pengembangan TQN Abad Kedua Puluh (Tasikmalaya: Yayasan Serba Bakti, 1995), 45.

17 Syaikh Tolhah merupakan murid langsung Syaikh Ahmad Khotib Sambas pendiri dan penggabung Tarekat Qodiriyah dan Naqsabandiyyah (TQN) yang berasal dari Kalimantan Barat dan menjadi guru besar Masjidil Haram di Mekkah. Bapaknya syaikh Tolhah adalah Kyai Tolabuddin putra Kyai Sayidin dan cucu Kyai Radfuddin. Para kyai tersebut merupakan tokoh ulama besar di masanya. Lihat Sri Mulyati, Peran Edukasi., p. 200-201.

${ }^{18}$ Para Santri yang menimba ilmu kepada Syaikh Cholil tersebut, selanjutnya menjadi tokohtokoh ulama besar di zamannya. Lihat Zamakhsari Dhofier, Tradisi Pesantren., 92.
} 
1905 mendirikan pondok pesantren sekaligus zawiyah khusus pengamalan TQN di daerah tepi hulu sungai Citanduy. Sekarang tempat ini dikenal dengan nama Suryalaya, diambil dari istilah sunda yang bermakna Surya berarti matahari, dan Laya yang berarti tempat terbit, sehingga makna Suryalaya secara harfiah mengandung arti tempat matahari terbit. ${ }^{19}$

Pada awalnya Abah Sepuh sempat bimbang tentang pendirian Pondok Pesantren ini, karena banyaknya rintangan dari kolonial Belanda dan orang-orang yang tidak sepaham dengan tarekat. Akan tetapi sang guru, Syaikh Tholhah bin Tolabudin memberikan motivasi, dorongan, dan bimbingan khusus kepada Abah Sepuh, bahkan Syaikh Tolhah pernah tinggal beberapa hari di Suryalaya sebagai wujud restu dan dukungannya. Tepat pada tahun 1908, tiga tahun setelah berdirinya Pondok Pesantren Suryalaya, Abah Sepuh mendapatkan khirqoh ${ }^{20}$ dari Syaikh Tholhah bin Tolabudin sebagai mursyid resmi Tarekat Qodiriyyah Naqsabandiyyah. ${ }^{21}$

Hubungan Abah Sepuh dengan Syaikh Tolhah dipererat dengan terjalinnya pernikahan antara puteri Abah Sepuh yang bernama H. Sukanah dengan Raden H.K. Munadi seorang putera Syaikh Tolhah. Hubungan kekeluargaan itu memperbesar dukungan terhadap pendirian Pondok Pesantren Suryalaya. ${ }^{22}$ Akhirnya, Abah Sepuh menjadi lebih yakin dan semangat untuk menjalankan amalan TQN di Pondok Pesantren Suryalaya dan lebih memperoleh posisi kharismatik di tengah-tengah masyarakat. Pada tahun 1910 sampai dengan 1930, Abah Sepuh diminta terlibat dalam arena politik praktis dengan menjadi penasihat di tiga wilayah kabupaten, yaitu menjadi penasihat Bupati Tasikmalaya, Bupati Ciamis, dan Bupati Bandung. Abah Sepuh pun diminta sebagai penasihat bagi

19 “Sejarah Pondok Pesantren Suryalaya”, http://suryalaya.org/ver2/sejarah.html, akses tanggal 10 Desember 2011.

${ }^{20}$ Khirqoh adalah sebuah bentuk legitimasi penguatan sebagai guru mursyid yang akan melaksanakan estafet kemursyidan dalam sebuah kelompok Tarekat.

${ }^{21}$ Unang Sunardjo, Menelusuri Perjalanan...,28.

22 Juhaya S. Praja dan Zaenal Abidin Anwar, "Pengaruh TQN PP. Suryalaya di Dalam dan Luar Negeri”, dalam Thoriqot Qodiriyyah Naqsyabandiyyah, ed Harun Nasution (Tasikmalaya: Institut Agama Islam Latifah Mubarokiyah, 1990) p. 198. Lihat juga, Sri Mulyati, dkk. Mengenal dan Memahami Tarekat-tarekat Muktabaroh di Indonesia, (Jakarta: Kencana, 2005), 269. 
Tentara Indonesia pada masa perang kemerdekaan tahun 1945-1949. Jabatan ini diamanahkan kepadanya sampai di usia terakhirnya pada tahun $1956 .^{23}$

Peran Abah Sepuh dalam memperjuangkan pendidikan sufistik saat itu adalah didirikannya majlis ta'lim hingga pondok pesantren yang kemudian menjadi sebuah lembaga yang menjadi rujukan atau terpaan bagi setiap lapisan masyrakatbaik dari dalam Negerimaupun luar negri, hal tersebut tetap berlangsung hingga saat ini. ${ }^{24}$

Semasa hidupnya, Abah Sepuh mempunyai tujuh istri. Istri pertamanya ibu Jubaedah dari Tasikmalaya dianugrahi seorang putri yang bernama Siti Sufiah. Istri ketiganya yang bernama Siti Juhriyah dianugrahi delapan putra putri, yaitu Siti Sukanah, Muhammad Malik, A. Mahmud Abdullah, H. Sa'adah, Ahmad Shohibulwafa Tajul Arifin (Abah Anom), Nur Wasi'ah, Didah Rosidah, dan Siti Sumayah Juhriyah. Istri kelimanya bernama ibu Enok, dianugrahi seorang putra bernama Noor Anom Mubarok. Abah Sepuh tidak mempunyai anak dari isteri kedua, keempat, keenam, dan ketujuhnya. ${ }^{25}$

\section{Biografi Abah Anom}

Sebutan Abah Anom merupakan panggilan istilah Sunda yang berarti Ayah Muda, sebutan kehormatan untuknya ketika masih muda sudah menjadi kyai. Abah Anom dilahirkan pada tanggal 1 Januari 1915 dan meninggal dunia pada tanggal 5 September 2011. Ketika kecilnya, Abah Anom masuk Sekolah Dasar Belanda di Ciamis antara tahun 1925-1929, kemudian melanjutkan Sekolah Menengah di Ciawi Tasikmalaya (1929-1931). Pada usia 18 tahun, Abah Anom telah diberi wewenang untuk menjadi wakil talqin ${ }^{26}$ oleh Mursyid TQN Abdullah Mubarok. Ia kemudian mempelajari Agama Islam secara mendalam di beberapa pesantren besar, seperti di Cicariang Cianjur,Pesantren Jambudipa dan Gentur di Cianjur.Kemudian

\footnotetext{
${ }^{23}$ Ibid., 269-270.

${ }^{24}$ Negara Pasundan semacam negara boneka yang dibentuk Belanda untuk memecah belah NKRI. Sri Mulayati, Peran Edukasi., p. 206-207.

${ }^{25}$ Ibid., p. 207-208. Lihat juga Unang Sunardjo, Menelusuri.,46.

${ }^{26}$ Wakil Talqin adalah orang yang dipercaya oleh Mursyid untuk mengajarkan dzikir kepada masyarakat yang mau ditalqin (baiat), karena keterbatasan ruang dan waktu, Mursyid TQN Suryalaya mengangkat beberapa wakil talqinnya untuk membaiat masyarakat di setiap penjuru daerah. Talqin sendiri secara harfiah berarti pembelajaran, di dalam TQN Suryalaya Talqin adalah proses pembelajaran dzikir dengan media ruhiah untuk menanamkan bibit dzikir ke dalam qolbu manusia, agar qolbunya terus aktif bisa terhubung terus kepada Allah. Lihat Wahfiudin Sakam, modul Kursus Tashawuf: Membangun Qalbu Insani, diselenggarakan di Masjid Al-Hijrah, Tempe-New South Wales Australia, tanggal 19 Juni 2011. Lihat juga Sri Mulyati, Peran Edukasi., p. 112.
} 
di Pesantren Cirenggas Cimalati Sukabumi Abah Anom mendapatkan ilmu Hikmah,beladiri pencak silat dan tarekat dari Kyai Aceng Mumu. Ia juga berlatih spiritual (riyadhoh) langsung dibawah bimbingan ayahnya. Ia juga mencari ilmu di Bangkalan Madura bersama kakaknya H.A. Dahlan dan KH. Fakih. ${ }^{27}$

Abah Anom menikah dengan Euis Ru'yanah pada tahun 1938 pada usia 23 tahun. Di tahun yang sama ia pergi ke Makkah ditemani oleh keponakannya Simri Hasanudin dan menetap selama 7 bulan untuk belajar tasawuf dan tarekat kepada seorang wakil talqin Abah Sepuh yang bernama syaikh Romli Garut yang sedang mukim di Jabal Qubaish dekat kota Makkah. Setahun kemudian pada 1939, Abah Anom kembali ke Suryalaya dan langsung membantu Abah Sepuh untuk mengembangkan pesantren Suryalaya. Dari perkawinannya dengan Ibu Euis Ru'yanah (meninggal tahun 1978) Abah Anom dikaruniai 13 putra-putri. Yaitu Dudun Nursaidudin, Aos Husni Falah, Nonong, Didin Hidir Arifin, Noneng Hesyati, Endang Ja'far Shidik, Otin Khodijah, Kankan Zulkarnaen, Memet Ruhimat, Ati Unsuryati, Ane Utia Rohyani, Baban Ahmad Jihad, dan Nia Iryanti. Dari istri keduanya Yoyoh Yosfiah (dinikahi tahun 1978) dikaruniai seorang putra bernama Ahmad Masykur Firdaus. ${ }^{28}$

Pada tahun 1945-1949 Abah Anom juga aktif membantu perang kemerdekaan. Ketika tahun 1953 Indonesia sedang masa orde lama, Abah Anom secara resmi ditetapkan sebagai pimpinan Pondok Pesantren Suryalaya sekaligus wakil talqin dari Abah Sepuh.Sepanjang periode 1953-1962, Abah Anom aktif dalam membantu Dewan Angkatan Perang Indonesia berperang melawan pemberontakan Kartosuwiryo. Selama tahun 1953-1995 aktif membantu pemerintah dalam program-programnya, seperti bidang pertanian, lingkungan hidup, pendidikan, ekonomi, sosial, kesehatan, dan politik. Atas kiprahnya itu, Abah Anom sering mendapatkan pujian dan penghargaan dari pemerintah seperti Satya Lencana Bakti Sosial (penghargaan untuk pengabdian sosial), Kalpataru (penghargaan untuk pegiat lingkungan).Kontribusi yang sangat populer dari Abah Anom adalah pembentukan Inabah sebagai pusat rehabilitasi mental para pecandu Narkoba. Sampai saat ini, Inabah bentukan Abah Anom sudah mencapai 21 pondok

\footnotetext{
${ }^{27}$ Unang Sunardjo, Menelusuri Perjalanan., 47-48.

${ }^{28}$ Ibid., 48.
} 
Inabah yang tersebar di pulau Jawa, Kalimantan, Sumatra, dan di luar negri seperti di Singapura dan Malaysia. Peran ini sangat bermanfaat untuk generasi bangsa dan bekerjasama dengan Badan Narkotika Nasional (BNN). ${ }^{29}$

Kontribusi Abah Anom dalam bidang pendidikan sufistik cukup banyak dirasakan manfaatnya oleh masyarakat sekitar. Sejak berdiri tahun 1905 sampai sekarang (100 tahun lebih) Pondok Pesantren Suryalaya sudah memiliki lembaga pendidikan yang lengkap, mulai TK, SMP Islam, MTs, SMA, SMK, MA, dan perguruan tinggi Institut Agama Islam Latifah Mubarokiyah (IAILM) juga Sekolah Tinggi Ilmu Ekonomi (STIE) Latifah Mubarokiyah. Dalam bidang ekonomi, Abah Anom mendirikan koperasi HIDMAT (Hidup Masa Tarekat), pasar rakyat rutin manakib setiap bulan pada tanggal 11 Hijriyah. Dalam bidang kesehatan, Abah Anom mendirikan Inabah sebagai pusat rehabilitasi pecandu narkoba yang sudah diakui secara internasional oleh International Federation of Non-Government Organization (IFNGO) PBB, yaitu penghargaan Distinguished Servis Award. Dalam bidang teknologi informasi, Abah Anom mendirikan stasiun radio Inayah FM, radio ini juga dijadikannya sebagai media sosialisasi TQN Suryalaya ke seluruh daerah. Dengan fasilitas audio streaming di internet, siaran radio ini bisa diakses dari seluruh dunia. ${ }^{30}$

\section{Naskah Tanbih Mursyid TQN Suryalaya}

Naskah tanbih adalah sebuah nasehat agama yang dianugrahkan oleh Abah Sepuh kepada Abah Anom pada tanggal 13 Februari 1956 (11 tahun pasca proklamasi kemerdekaan RI), yang berisi wujud perintah (wasiat) yang disebarkan untk semua ikhwan (semua pengikut/pengamal/murid Mursyid TQN Suryalaya), baik laki-laki maupun perempuan, muda ataupun tua, sebagaimana berikut;

"Kita adalah tempat dimana orang dating dengan membawa pertanyaan mereka tentang TQN, dan kami hadirkan dengan penuh ketulusan suatu wasiat

\footnotetext{
${ }^{29}$ Dengan menggunakan metode inabah ini, dihasilkan kesembuhan para santri bina dengan capaian $80 \%-92 \%$, bahkan memiliki relevansi yang positif dengan penurunan gejala-gejala keluhan fisik maupun gejala somatisasi lainnya. Dengan metode ini juga, Abah Anom selaku penemu pertama mendapatkan penghargaan dari United Nations (PBB) atas perannya menyembuhkan pecandu narkoba. Lihat Agus Samsul Bassar, "Implementasi Nilai-nilai Sufistik dalam Kurikulum Institut Agama Islam Latifah Mubarokiyah" dalam Jurnal Ilmiah Tasawuf dan Kebudayaan Islam, edisi 1(tahun 2009) p. 105. Sebagai pembanding, lihat juga Sri Mulyati, Peran Edukasi., p. 214 .

${ }^{30}$ Ajid Thohir, dkk. Tarekat Qodiriyyah., P. 50-54.
} 
kepada semua murid, untuk menjadi perhatian yang seksama atas segalanya, yaitu tidak melakukan tindakan yang melawan terhadap aturan-aturan Negara dan agama. Mematuhi keduannya dengan sewajarnya, itu adalah sikap dari seorang manusia yang teguh dengan keyakinannya, yang mampu memanifestasikan kesediaannya untuk mengabdi kepada kedua-duanya (Negara dan Agama) dan menunjukkan ketaatan kepada Allah SWT. Tindakan ini menunjukkan sebagai bukti bakti terhadap Negara dan agama. Pahamilah wahai murid-murid, janganlah tergoda oleh keinginan yang tidak baik, atau terpengaruh oleh godaan setan. Sadarlah dan berhati-hatilah terhadap jalan yang salah, yang melawan terhadap perintah agama dan Negara dalam rangka menghindari ketertarikan terhadap bisikan-bisikan setan yang selalu merasuki kedalam relung hati kita". 31

Berdasarkan hasil analisis terhadap isi teks tanbih Mursyid TQN di atas,, maka dapat di pahami bahwa TQN menyediakan jalan yang terbaik menuju keberhasilan yang ideal. Hal ini merujuk kepada kalimat yang selalu diucapkan setiap selesai melaksanakan shalat fardlu bagi setiap pengikut (Ikhwan wa al-akhawat) TQN ini, yaitu kalimat "Ilahii anta Maqshudi wa ridlaka mathlubi a'tini mahabbataka wa ma'rifataka" yang artinya "Wahai Tuhanku hanya kepada Engkaulah tujuanku dan keridlaan-Mulah yang aku cari; anugerahkanlah aku kemampuan untuk mencintai-Mu dan mengetahui-Mu (Ma'rifat)". ${ }^{32}$

Identifikasi arti penting dari kalimat do'a ini antara lain ialah; Pertama, pendekatan (Taqarrub) kepada Allah SWT, maksudnya adalah bagaimana membuat dirinya semakin dekat kepada Allah melalui ibadah sehingga tidak ada penghalang antara hamba ('abid) dengan yang dipuja (Ma'bud), atau antara sang pencipta (Khaliq) dengan yang diciptakan (Makhluq);Kedua, mengikuti jalan yang telah digariskan oleh Allah SWT, kedua-duanya dalam beribadah dan diluar ibadah, karena dalam tiap-tiap tindakan, manusia perlu bahkan wajib mengikuti perintah Allah dan menjahui segala apa yang dilarang; dan Ketiga, cinta dan ma'rifat kepada Allah SWT, yaitu perpaduan antara cinta dan pengetahuan yang jelas tentang Allah SWT (Ma'rifatullah) yakni cinta yang terdiri dari kekuatan dan kejujuran dan hati.

Jika tumbuh rasa cinta (Mahabbatulla), kebijaksanaan akan tampak, bersamaan dengan kualitas yang lain; yang akan menjadikan seseorang jujur dengan sungguh-

\footnotetext{
${ }^{31}$ Ringkasan dari teks tanbih Tarekat Qadiriyyah Naqsyabandiyyah Suryalaya.Abah Sepuh, Tanbih dalam K.H. A. Shohibulwafa Tajul 'Arifin, Tanbih dan Asas Tujuan Thariqat Qadiriyyah Naqsyabandiyyah, (Tasikmalaya: Yayasan Serba Bakti Pondok Pesantren Suryalaya, 1976), 8-9

${ }^{32}$ A. Shohibulwafa Tajul 'Arifin, 'Uqudu al-Juman, (Tasikmalaya: Yayasan Serba Bakti Pondok Pesantren Suryalaya, 1999), 23
} 
sungguh baik lahiriyah maupun batiniyah. Ia akan mampu bertindak dengan tepat dan akan dapat menempatkan segala sesuatu pada tempatnya. Dari perasaan cinta (Mahabbatullah) tersebut, akan berlanjut kepada cinta terhadap semua makhluk. ${ }^{33}$

Masih dalam konteks interpretasi dari teks tanbih Mursyid TQN Suryalaya, Mursyid TQN ini tidak mengindikasikan bahwa TQN satu-satunya cara untuk mencapai tujuan yang diinginkan, karena beliau jugag memberikan pengakuan terhadap tarekattarekat yang lain. Hal ini dapat dibuktikan dengan beberapa acuan Abah Anom dalam kitabnya (Mifatahu as-Shudur) terhadap tarekat Syadziliyyah dan Kubrawiyyah disamping ajaran dari mursyid-mursyid Qadiriyyah dan Naqsyabandiyyah. ${ }^{34}$ Kualifikasi tertentu juga diperlukan bagi seorang Mursyid, termasuk bahwa ia pintar dalam hal-hal pendektan kepada Nabi Muhammad SAW. Seorang yang religius ( 'alim) bisa memandu orang menghindari jeratan dunia dan segala daya tariknya, melakukan disiplin pribadi di antaranya; makan lebih sedikit, tidur sedikit dan berbicara secukupnya, melakukan frekuensi shalat yang lebih, sedekah, dan puasa, bertingkah laku dengan baik; sabar, bersyukur, menyerahkan diri sepenuhnya hanya untuk Allah SWT, berkeyakinan, dermawan, dan penuh qana'ah, jujur, malu dan lain-lain ${ }^{35}$ Seorang Mursyid bertindak sebagai duplikat karakter Nabi SAW. melalui silsilah nuriyah (mata rantai cahaya karakter kemulyaan), sebagai lawan dari karakter dhuriyat(keturunan). Mursyid yang ideal ialah seorang yang mempersentasikan cahaya dari cahaya-cahaya para Rasul. Mursyid seperti inilah yang harus diikuti, karena keberadaan mereka sangat jarang ditemukan pada saat ini.

Tanbih Mursyid TQN Suryalaya memberikan penegasan dan pemahaman melalui pendidikan sufistiknya kepada seluruh Ikhwan TQN tentang upaya untuk melakukan hubungan yang ideal antara sesama manusia dengan sebaik mungkin, yaitu dengan menganjurkan ikhwan untuk dapat mempertunjukkan nilai kebaikan secara sosial yang diperoleh melalui kesucian hatinya yang bermuara pada keempat unsur setatus individu di dalam bermasyrakat sebagaimana berikut; Pertama, Ihwan harus menunjukkan rasa hormat terhadap yang lebih tinggi tingkatannya, baik secara rohani maupun setatus. Ini harus dilaksanakan agar dapat hidup bersama-sama dalam

\footnotetext{
${ }^{33}$ A. Shohibulwafa Tajul 'Arifin, Tanbih dan Asas Tujuan Thariqat Qadiriyyah Naqsyabandiyyah, (Tasikmalaya: Yayasan Serba Bakti Pondok Pesantren Suryalaya, 1976), 5-7

34 Harun Nasution,Thariqat Qadiriyyah Naqsyabandiyyah Sejarah Asal Usul Perkembangannya, (Tasikmalaya: Institut Agama Islam Latifa Mubarokiyah. 1990),134

${ }^{35}$ Muhammad Haqiqi al-Nazili, Khazinat al-Asrar Jahilat al-Adlkar, (Semarang: Usaha Jaya, 1996), 194
} 
keselarasan dan rasa saling hormat-menghormati sebagai timbal balik yang saling menguntungkan.

Kedua, jangan terlibat pertengkaran bagi setiap ikhwan yang mempunyai setatus/nasib/kedudukan yang sama dalam segala hal, sebaliknya mereka perlu memelihara suatu sikap sederhana, bekerja bersama untuk kepentingan TQN, Negara dan Agama. Dan pula tidak mempromosikan pertengkaran dan perselisihan (menghasud dan atau menebar kebencian kepada sesama).

Ketiga, janganlah menghina atau melakukan suatu yang tidak baik, janganlah bertindak angkuh terhadap golongan yang lebih rendah dari kita. Melainkan, orang harus simpatik agar supaya mereka merasakan bahagia, tidak merasa ditakut-takutidan janganlah menyakiti perasaan mereka. Sebaliknya mereka harus dipandu dengan nasihat yang lembut akan membuat mereka sadar bahwa mereka perlu berjalan di atas jalan yang benar.

Keempat, terhadap mereka yang lemah miskin (fakir miskin), para Ikhwan harus bersikap lembut, baik hati, dermawan, penyabar, dan murah senyum yang merupakan perwujudan dari kesadaran hati para ikhwan akan nasib mereka. Bayangkanlah kalau ada diposisi mereka. Oleh karena itu, janganlah untuk tidak punya rasa peduli. Wujudkanlah rasa dari mereka kebahagiaan karena berada disamping para ikhwan. Perlu disadari bahwa bahwa mereka bersetatus lemah dan atau miskin bukanlah atas kehendak mereka sendiri, melainkan adalah Qadrat Allah SWT. ${ }^{36}$

Sri Mulyati ${ }^{37}$ mengemukakan bahwa Abah Anom sangat tegas akan pentingnya mena'ati nilai-nilai pendidikan sufistik yang ada dalam naskah Tanbih Mursyid TQN Suryalaya. Hal ini merupakan kunci utama bimbingan TQN kepada seluruh Ikhwannya dan mencerminkan aliran Sunni dari sudut manapun. Abah anom mencoba untuk mengembangkan rasa saling pengertian antara beliau sendiri, ikhwan, masyrakat luas dan pemerintah.

\section{Kedudukan Tanbih Dalam Ajaran TQN Suryalaya}

Seluruh isi teks Tanbih selalu dibaca oleh murid-murid (Ikhwan) TQN Suryalaya dalam setiap ritual acara manakib. Urutan posisinya dibaca setelah pembacaan ayat suci

\footnotetext{
${ }^{36}$ Abah Sepuh, Tanbih dalam K.H. A. Shohibulwafa Tajul 'Arifin, Tanbih dan Asas Tujuan Thariqat Qadiriyyah Naqsyabandiyyah, 11-12

${ }^{3737}$ Sri Mulyati, Peran Edukasi Tarekat Qadiriyyah Naqsyabandiyah dengan Refrensi Utama Suryalaya, (Jakarta: Kencana, 2010) , 223
} 
al-Qur'an. Hal ini menunjukan pentingnya Tanbih ini bagi setiap ikhwan. ${ }^{38}$ Bahkan, menurut H.S. Nasution dalam bukunya Samudera Tanbih (1997), bahwa kedudukan Tanbih dalam Ajaran TQN Suryalaya mempunyai tujuh fungsi utama, yaitu: Pertama, Tanbih sebagai wasiat yang disampaikan oleh Seorang Guru Mursyid kepada setiap ikhwan TQN Suryalaya untuk diamalkan dengan totalitas dan sistemik, guna mencapai keselamatan dunia akhirat.

Kedua, Tanbih adalah amanat berupa tanggungjawab manusia selaku khalifah (pengganti) Allah, manusia selaku anak Adam tugasnya adalah memelihara dan mengurus setiap jengkal bumi dengan baik dan bermanfaat. Ketiga, Tanbih sebagai peringatan supaya manusia selalu taat melaksanakan perintah agama dan negara. Keempat, Tanbih sebagai pedoman bagi setiap ikhwan TQN Suryalaya dalam setiap perilakunya sehari-hari. Kelima, Tanbih sebagai tuntunan untuk selalu mengamalkan ajaran inti TQN Suryalaya, yaitu dzikir zahar dan dzikir khofi. Keenam, Tanbih sebagai bimbingan hubungan baik antara sesama manusia dan alam semesta. Dan ketujuh, Tanbih sebagai nasihat berupa nilai-nilai kasih sayang dari seorang Guru Mursyid kepada semua muridnya. Nasihat yang akan dilakukan bersama-sama untuk kepentingan bersama pula. $^{39}$

\section{Nilai-nilai Pendidikan Sufistik dalam Naskah Tanbih}

Nilai-nilai pendidikan sufistik berikut ini bermuara kepada beberap problematika kehidupan manusia yang selalu mendapatkan dorongan dari nafsu sendiri dan dorongan serta keinginan yang dibisikkan oleh Iblis/setan, guna melakukan hal-hal yang menyimpang dari aturan-aturan baik negara maupun Agama.

Abah Anom memberikan penjelasan bahwa biangnya penyakit hati adalah kesediaan menuruti godaan dan keinginan setan. Jika ,amusia mematuhi ini, sikap jahat bisa mengambil alih dirinya sendiri, seperti ketidaktahuan, kesombongan, kecemburuan, keangkuhan dan lain-lain. Ini akan menciptakan hal negatif seperti kekerasan dan kekasaran, dan ini akan mengakibatkan masyrakat bersifat individualistik, menghapus rasa kasih sayang yang menghubungkan orang bersama-sama. Dengan begitu, hilanglah

${ }^{38}$ Mamat Rachmat, Tanbih Dari Masa ke Masa (Tasikmalaya: Yayasan Serba Bakti PP. Suryalaya, 2005), p. 101.

${ }^{39}$ H. A. S. Nasution, Samudera Tanbih (Tasikmalaya: Yayasan Serba Bakti PP. Suryalaya, 1997), p. 29-43. 
perinsip gotong royong, kerendahan budi akan mengambil alih, kebenaran akan menjadi sia-sia, pembinasaan dan kepalsuan menyebar ketengah-tengah masyrakat. ${ }^{40}$

Lebih lanjut beliau memaparkan bahwa situasi seperti diatas dapat mendorong ke arah konflik kejam yang dapat mengakibatkan kematian ribuan orang. Hidup manusia akan diisi kesengsaraan dan penderitaan. Ketidakjujuran dan ketidakadilan juga akibat dari manusia yang merelakan diri mereka untuk diambil alih oleh penyakit atau keinginan hati ini dibiarkan hidup, maka perkembangan manusia terutama bangsa, akan terganggu, dan akhirnya gagal. ${ }^{41}$

Dalam pandangan Abah Anom, kondisi ini tidak dapat diabaikan begitu saja, karena dapat mempengaruhi kaum muda atau pelajar sebagai generasi bangsa, membuat mereka merasa bahwa masa depan mereka gelap, mereka akan terjerumus dalam suasana ketidakpastian, suram dan menyusahkan. Terkadang mereka punya keinginan mengendalikan perasaan tidak mengenakkan dengan cara-cara yang berbahaya bagi agama dan negara. Ketersesatan mereka akan mengakibatkan kerugian untuk negara dan bangsa. Abah Anom memaparkan bahwa hal ini terkadang kesalahan dari guru atau orang tua, kenyataan ini didasarkan pada sabda Nabi SAW. yang artinya; "Setiap Manusia dilahirkan dalam keadaan suci (Fithrah), maka orang tuanyalah yang memimpin anaknya menjadi Yahudi Nasrani, atau Majusi", ${ }^{42}$ dengan kata lain, tugas guru atau orang tua untuk memberikan contoh kepada anaknya tentang kebaikan hingga pada keturunan mereka. Oleh karena itu, mereka harus mengarahkan anak-anak mereka dengan ajaran agama yang sesuai, mengatur jalan spiritual agar tetap ada di jalan yang benar. Di sinilah Monotoisme Islam yang murni dapat ditemukan, sebab ia terkadang dalam manusia dan telah tertanam, berakar di dalam jiwa mereka. Perinsip ini sejalan dengan firman Allah dalam Q.S ar-Rum ayat 30 yang artinya:

"Maka hadapkanlah wajahmu kepada agama dengan selurus-lurusnya (sesuai dengan kecenderungan aslinya) itulah fitrah Allah, yang Allah menciptakan manusia dia atas fitrah itu. Itulah agama yang lurus. Namun kebanyakan orang tidak mengetahuinya."

Islam adalah fitrah yang memuat bimbingan Ilahi untuk manusia, meningkatkan kualitas dirinya di dunia dan akhirat, terutama ketika perasaan dan pikirannya terbatas dari khurufat takhayyul, yang merupakan dari macam-macam penyakit rohani. Dengan

\footnotetext{
${ }^{40}$ A. Shahibulwafa Tajul 'Arifin, Akhlak Al-Karimah al-Mahmudah Berdasarkan Mudawama Dzikrullah, (Tasikmalaya: Kutmas, 1983), 1

${ }^{41}$ Ibid, 2-3

${ }^{42}$ Hadits ini diriwayatkan oleh al-Thabroni, Ahmad Ibn Hambal, al-Darami, al-Hakim dan al-Baihaqi.
} 
naluri ini, kemauan pribadi dan aktivitasnya terbebas dari keinginan buruk dan godaan setan yang membelenggu. Seseorang tidak boleh tergantung pada sesama makhluk apa lagi setan, namun hanya kepada Allah SWT semata. ${ }^{43}$

Kekuatan iman yang memurnikan jiwa dapat juga membersihkan mereka dari sikap cemburu, angkuh, dengki, pemarah, merasa bangga atas keingkaran terhadap perintah negara dan Agama, liar dan ketidakadilan. Iman juga mendorong manusia untuk meningkatkan hidup mereka, seperti halnya kesadaran hukum, membawa ketentraman dan kebahagiaan baik bagi pribadi atau masyrakat pada umumnya. Hal ini didasarkan pada firman-Nya potongan ayat Q.S al-Ma'idah (5:4)n yang artinya; dan bertakwalah kepada Allah, "Sesungguhnya Allah Amat cepat hisab-Nya", Q.S, AlImran (3:134) yang artinya; . “(yaitu) orang-orang yang menafkahkan (hartanya), baik di waktu lapang maupun sempit, dan orang-orang yang menahan amarahnya dan mema'afkan (kesalahan) orang. Allah menyukai orang-orang yang berbuat kebajikan”.dan Q.S. al-Kahfi (18:88) yang artinya; “Adapun orang-orang yang beriman dan beramal saleh, Maka baginya pahala yang terbaik sebagai balasan, dan akan Kami titahkan kepadanya (perintah) yang mudah dari perintah-perintah kami"44

Abah Anom mengemukakan kembali, bahwa unsur-unsur yang dibutuhkan untuk kemajuan dhahir dan batin, didunia ini dan alam selanjutnya, hanya dapat dicapai melalui kebajikan yang dilakukan dengan kedamaian hati, dan dalam bersikap tunduk dan tenang (khusyu'). Semua ini tergantung pada keyakinan kuat kepada Allah SWT. Oleh karena itu, kepercayaan atau iman membantu mengusir keraguan, keangkuhan atau kemunafikan, yang merupakan penyebab utama penyakit hati. ${ }^{45}$

Abah Anom memaparkan salah satu Hadi Nabi SAW. yaitu, "Mengingat Allah dapat memperoleh obat (mustajab) untuk menyembuhkan semua penyakit.” Dzikrullah adalah teknik untuk pemindahan kekurangan ini. Nabi bersabda, bahwa ada cara membersihkan hati, yakni dzikrullah. Interpretasi Abah anom terhadap potongan hadist ini ialah penyebab semua penyakit seperti itu adalah ketidakpedulian terhadap Allah SWT., ketidakingatan hati, atau ketidakingatan pikiran kepada Allah., semua disebabkan oleh hati dan pikiran yang dipengaruhi oleh bisikan nafsu atas, adanya

\footnotetext{
${ }^{43}$ A. Shohibulwafa Tajul 'Arifin, Akhlak al-Karimah, 5

${ }^{44}$ A. Shohibulwafa Tajul 'Arifin, Akhlak al-Karimah, ,. 6-7

${ }^{45}$ A. Shohibulwafa Tajul 'Arifin, Akhlak al-Karimah, ,.8
} 
dorongan dari setan. Sehingga hati dan pikiran diisi oleh keinginan untuk hal-hal yang lain, seperti kekayaan, kebangsawanan, posisi, pujian, bujukan dan lain-lain. ${ }^{46}$

Apa bila hati selalu diisi dengan kalimat suci (dzikrullah), pikiran akan terhubungkan kepada Allah SWT, oleh karena itu pengaruh dzikir akan sangat tampak dalam sikap batin manusia dan akan tumbuh atau teraplikasikan melalui perbuatan/tindakan kebaikan, yakni menjalankan perintah Allah SWT dan Utusan-Nya.

Bangunan 'akidah/iman diri seseorang adalah tidak cukup untuk mengusir semua keinginan atau godaan nafsu atau setan. Hal ini mengacu pada Firman Allah SWT Q.S. al-Ra'du (13:28) yanga artinya; “(yaitu) orang-orang yang beriman dan hati mereka manjadi tenteram dengan mengingat Allah. Ingatlah, hanya dengan mengingati Allah-lah hati menjadi tenteram". Oleh karena itu 'akidah/iman yang kuat harus secara berhat-hati dipelihara, karena iman adalah kekuatan utama yang membantu memenuhi dan untuk mendorong semua aktivitas manusia di dunia ini dan Alam selanjutnya. ${ }^{47}$ Lebih lanjut Abah Anom memaparkan bahwa sikap ini perlu ketika sesorang mengejar untuk berintraksi langsung dengan Allah SWT (hablum min Allah) dan berintraksi dengan sesama manusia (hablum min al-Nas). Kebajikan kepada manusia (mu'amalat) meliputi hati yang tulus, jujur, dan berbuat karena Allah, seperti tidak pernah lupa kepada Allah dalam segala aktivitasnya, seperti tersebut dalam firman-Nya Q.S. Ali Imran (3:161). Kebajikan yang diakui Allah SWT adalah perbuatan seseorang yang hatinya tidak munafik, dan kebajikan seperti inilah yang akan dianugrahi pahala berlipat-lipat oleh Allah SWT. Hal ini Abah Anom merujuk pada firman-Nya Q.S. an-Nahl (16:97). ${ }^{48}$

Aktivitas sesorang yang sabar, pikirannya terkondisikan untuk selalu mengingata Allah SWT. dalam keadaan ia sedang bekerja, berdagang, belajar, berjuang dan lain-lain, adalah aktivitas untuk di jalan menuju Allah. Abah Anom disini mengemukakan pemahaman dari fiman-Nya; "Manusia seperti itu adalah orang yang melaksanakan dzikrullah, tidak sedang di alihkan atau tidak sedang dipengaruhi oleh aktivitas hariannya.Sebaliknya ia sedang beristiqamah dalam melakukan shalat dan bersedekah" (Q.S. an-Nur 24:37). Berdasarkan interpretasi dari ayat ini Abah anom berkesimpulan bahwa setiap manusia seharusnya dan bahkan wajib selalu ingat Allah

\footnotetext{
${ }^{46} \mathrm{~A}$. Shohibulwafa Tajul 'Arifin, Akhlak al-Karimah, ,.9

${ }^{47}$ A. Shohibulwafa Tajul 'Arifin, Akhlak al-Karimah..,14

${ }^{48}$ A. Shohibulwafa Tajul 'Arifin, Miftah al-Shudur..,315
} 
SWT., taat beribadah, terutama dalam melaksanakan shalat, zakat dan puasa yang mendasari inti kebijakan dalam mengimplementasikan upaya intraksi manusia dengan Allah (hablum min Allah) dan juga wujud implementasi dari intraksi antara sesama manusia (hablum min al-Nas). Seseorang tidak boleh mengabaikan iman, kesabaran dan zdikir ini, entah dia seorang karyawan, pejabat, manusia kaya, atau bahkan ilmuan, karena hanya dengan iman yang kuat dan kesabaran dirinya ia dapat memecahkan berbagai kesulitan. ${ }^{49}$

Hati yang dipenuhi dengan kalimat Allah (dzikrullah), adalah hati yang berdenyut dengan irama keagungan dan kemuliaan Allah. Pikiran orang yang memiliki hati seperti itu adalah bersyukur kepada Allah SWT. seluruh hidupnya dipersembahkan hanya kepada Allah, sehingga ia memiliki keperibadian yang dihiasi dengan sikap terpuji, manusia seperti itu cinta (mahabbah) kepada Allah pada khususnya, dan mempunyai perasaan rasa kasihan kepada manusia dan alam semesta secara umum. ${ }^{50}$

\section{Penutup}

Berdasarkan hasil penelitian di atas dapat disimpulkan bahwa, terdapat empat rumusan wasiat pendidikan sufistik yang terkandung dalam naskah tanbih Mursyid TQN Suryalaya sebagaimana berikut: Pertama, Ihwan harus menunjukkan rasa hormat terhadap yang lebih tinggi tingkatannya, baik secara rohani maupun setatus. Kedua, Jangan terlibat pertengkaran bagi setiap ikhwan yang mempunyai setatus/nasib/kedudukan yang sama dalam segala hal, sebaliknya mereka perlu memelihara suatu sikap sederhana, bekerja bersama untuk kepentingan TQN, Negara dan Agama. Dan pula tidak mempromosikan pertengkaran dan perselisihan (menghasud dan atau menebar kebencian kepada sesama). Ketiga, Janganlah menghina atau melakukan suatu yang tidak baik, janganlah bertindak angkuh terhadap golongan yang lebih rendah dari kita. Melainkan, orang harus simpatik agar supaya mereka merasakan bahagia, tidak merasa ditakut-takutidan janganlah menyakiti perasaan mereka. Sebaliknya mereka harus dipandu dengan nasihat yang lembut akan membuat mereka sadar bahwa mereka perlu berjalan di atas jalan yang benar. Keempat, Terhadap mereka yang lemah miskin (fakir miskin), para Ikhwan harus bersikap lembut, baik hati, dermawan, penyabar, dan murah senyum yang merupakan perwujudan dari kesadaran

\footnotetext{
${ }^{49}$ A. Shohibulwafa Tajul 'Arifin, Miftah al-Shudur..,75

${ }^{50}$ A. Shohibulwafa Tajul 'Arifin, Akhlak al-Karimah, ,.17
} 
hati para ikhwan akan nasib mereka. Bayangkanlah kalau ada diposisi mereka. Oleh karena itu, janganlah untuk tidak punya rasa peduli. Wujudkanlah rasa dari mereka kebahagiaan karena berada disamping para ikhwan. Perlu disadari bahwa bahwa mereka bersetatus lemah dan atau miskin bukanlah atas kehendak mereka sendiri, melainkan adalah Qadrat Allah SWT. 


\section{Daftar Pustaka}

Abdullah, Hawas, 1980. Perkembangan Ilmu Tasawuf dan Tokoh-tokohnya di Nusantara, Surabaya, al Ikhlas,

Ahmadi, 2005. Ideologi Pendidikan Islam, Pradigma Humanisme Teosentris, Yogyakarta: Pustaka Pelajar,

'Arifin, 2006. Ahmad Shohibulwafa Tajul, Uqudul Juma'an, Bandung,: Wahana Grafika,

, Miftah al-Shudur 2006. “Kunci Pembuka Hati melalui Pendekatan Dzikrullah, Bandung,: Wahana Grafika,

1983. Akhlak Al-Karimah al-Mahmudah Berdasarkan Mudawama Dzikrullah, Tasikmalaya: Kutmas,

1976. Tanbih dan Asas Tujuan Thariqat Qadiriyyah Naqsyabandiyyah, Tasikmalaya: Yayasan Serba Bakti Pondok Pesantren Suryalaya,

Al-Hijazi, Hasan Bin Ali, 2001. Manhaj Tarbiyah Ibnu Qoyyim, Jakarta: Pustaka Al-Kausar,

Al-Nazili, Muhammad Haqiqi, 1996, Khazinat al-Asrar Jahilat al-Adlkar, Semarang: Usaha Jaya,

Arief Furchan dan Agus Maimun, 2005. Studi Tokoh: Metode Penelitian Mengenai Tokoh (Yogyakarta: Pustaka Pelajar,

Bassar, Agus Samsul, 2009. "Implementasi Nilai-nilai Sufistik dalam Kurikulum Institut Agama Islam Latifah Mubarokiyah", dalam JurnalTasawuf dan Kebudayaan Islam, edisi 1 tahun

Depertemen Agama RI, Al-Quran dan terjamahannya, yayasan penyelenggaraan penafsir/penerjamah Al-Qur'an.

Dhofier, Zamakhsari, 1990.Tradisi Pesantren: Studi Tentang Pandangan Hidup Kyai, Jakarta: LP3ES.

Klaus, Krippendorff, 2004. Content Analysis: An Introductions to its Methodology (Second Edition), California: Sage Publication.

Majid, Abdul, 2011. Pendidikan Karakter Perspektif Islam, Bandung: PT Remaja Rosdakarya.

Margono, S, 2000. Metodologi Penelitian Pendidikan, Jakarta: PT Asdi Mahasatya, Cet, ke-2.

Muhaimin, Wacana Pengembangan Pendidikan Islam, Yogyakarta: Pustaka Pelajar, 2003

1993. Pemikiran Pendidikan Islam;Kajian Filosofis dan kerangka Dasar Operasionalisasinya,. Bandung: PT Triganda Raya.

Mulyati, Sri, dkk. 2005. Mengenal dan Memahami Tarekat-tarekat Muktabaroh di Indonesia, Jakarta: Kencana. 
2010. Peran Edukasi Tarekat Qodiriyah Naqsyabandiyah dengan Referensi Utama Suryalaya, Jakarta: Kencana

Nasution, H. A. S. 1997. Samudera Tanbih, Tasikmalaya: Yayasan Serba Bakti PP. Suryalaya.

1997. Samudera Tanbih, Tasikmalaya: Yayasan Serba Bakti PP. Suryalaya

Praja, Juhaya S. dan Zaenal Abidin Anwar, 1990. "Pengaruh TQN PP. Suryalaya di Dalam dan Luar Negeri", dalam Thoriqot Qodiriyyah Naqsyabandiyyah, ed. Harun Nasution, Tasikmalaya: Institut Agama Islam Latifah Mubarokiyah.

Rachmat, Mamat, 2005. Tanbihdari Masa ke Masa, Tasikmalaya: Yayasan Serba Bakti PP. Suryalaya.

Sahlan, Aswan, 2012. Desain Pembelajaran Berbasis Pendidikan Karakter, Yogyakarta: Ar-Ruzz Media.

Salamah, Ummu, 2005. Sosialisme Tarekat: Menjejaki Tradisi dan Amaliah Spiritual Sufisme Bandung: Humaniora.

Soejonodan Abdurrahman, 1999. Metode Penelitian suatu Pemikiran dan Penerapannya Jakarta: Reneka Cipta.

Syiraj, Said Aqil, 2006. Tasawuf Sebagai Kritik Sosial, mengedepankan Islam sebagaiinfirai, bukanAsfirasi, Bandung, Mizan.

Sunardjo, Unang, 1995. Menelusuri Perjalanan Sejarah Pondok Pesantren Suryalaya, Pusat Pengembangan Tarekat Qodiriyah wa Naqsabandiyyah Abad Kedua puluh, Tasikmalaya: Yayasan Serba Bakti Pondok Pesantren Suryalaya.

Thohir, Ajid, dkk. 2011. Tarekat Qodiriyyah Naqsabandiyyah Pondok Pesantren Suryalaya Membangun Peradaban Dunia, Tasikmalaya: Mudawwamah Warohmah Press.

Yahya,Kadirun, 1982. Penjelasan Tentang Wasilah dan Mursyid, Universitas Panca Budi Medan. 